Eixo Temático: Biologia Aplicada

\title{
ET-09-014 \\ COMPARAÇÃO DA ASSEMBLEIA DE MORCEGOS ENTRE UMA PLANTAÇÃO DE EUCALIPTOS E A FLORESTA ATLÂNTICA NO NORDESTE, BRASIL
}

Anna Claudia Aca Ferreira ${ }^{1}$, Tatiane França Meloํㅡ, Danúbia Guimarães Silva ${ }^{1}$, Martin Alejandro Montes ${ }^{2}$, Ana Cristina Lauer Garcia ${ }^{1}$

${ }^{1}$ Programa de Pós-Graduação em Saúde Humana e Meio Ambiente. Centro Acadêmico de Vitória. Universidade Federal de Pernambuco - UFPE. Rua do Alto do Reservatório, s/n. Vitória de Santo Antão-PE. (CEP 55608-680).

${ }^{2}$ Laboratório de Genética. Bioquímica e Sequenciamento de DNA. Universidade Federal Rural de Pernambuco - UFRPE. Rua Dom Manoel de Medeiros, s/n. Recife-PE. (CEP 52171-900).

$$
\text { http://dx.doi.org/10.21472/congrebio2016.et-09-014 }
$$

\section{RESUMO}

A Floresta Atlântica é um dos principais biomas do Brasil que desperta interesse nos estudos científicos, devido à alta diversidade e presença de espécies endêmicas. No entanto, com o avanço das construções civis e das atividades agropecuárias uma parte deste bioma está sendo substituída por plantações de monoculturas e pastagens. A Sub-Região da Floresta Atlântica brasileira denominada de Centro de Endemismo de Pernambuco, situada ao norte do Rio São Francisco, é uma das regiões mais atingidas por essa destruição. Alguns estudos sugerem que a substituição da Floresta Atlântica por plantações de eucaliptos pode manter e sustentar a diversidade de alguns grupos taxonômicos, entre os quais os morcegos. Estes organismos apresentam funções importantes nos serviços ecossistêmicos, sendo sensíveis a fragmentação e degradação de florestas. Diante desse contexto, o objetivo do presente estudo foi comparar a riqueza, a abundância de morcegos, bem como a influência da sazonalidade sobre estes parâmetros em uma área de floresta nativa e uma plantação de eucaliptos no domínio da Floresta Atlântica no Centro de Endemismo de Pernambuco. As coletas dos morcegos foram realizadas por um período de oito dias, distribuídos igualmente entre a época de maior e menor pluviosidade nas duas áreas de estudo. Foram capturados 55 morcegos no fragmento de Floresta Atlântica e 24 na plantação de eucaliptos, contabilizando seis espécies. A partir dos dados obtidos, foi possível concluir que a riqueza e a abundância da assembleia de quirópteros não apresentou diferenças significativas entre os locais e entre as estações seca e chuvosa. (CNPQ/CAPES).

Palavras-chave: Abundância; Fragmento; Riqueza.

\section{INTRODUÇÃO}

As florestas tropicais úmidas são um dos principais tipos de vegetação do mundo e ocorrem essencialmente em zonas equatoriais e intertropicais. Estas florestas são tipicamente formadas por dosséis fechados, sempre-verdes, com árvores de 25 metros de altura ou mais, constituídas por folhas largas, e também por uma considerável abundância de trepadeiras e epífitas. Estas florestas apresentam variação na altitude, podendo ser encontradas desde o nível do mar até aproximadamente 1500 metros, refletindo em diferentes fisionomias (TURNER, 2001).

Atualmente a extensão das florestas tropicais úmidas está diminuindo de forma acelerada em todo o planeta, devido à transformação de seus territórios em áreas de moradias e 
construções, zonas de agropecuária e plantações de monoculturas de ciclo longo para exploração madeireira. Este cenário tem despertado o interesse do quanto estas alterações ambientais impactam a conservação biológica (GARDNER et al., 2009). Dentro desta problemática, alguns autores argumentam, por exemplo, que as plantações de eucaliptos comportam baixa diversidade de espécies em comparação com o ambiente existente antes destas plantações (LAW et al., 2011). Outros estudos, no entanto, têm mostrado uma considerável biodiversidade associada a estas plantações, com níveis similares de riqueza em comparação com as florestas nativas antes encontradas nesses locais (SILVA et al., 2014).

Um exemplo de floresta tropical úmida no Brasil é a Floresta Atlântica, a qual se destaca por sua elevada diversidade de espécies, e por sua evidente quantidade de endemismos. Ao mesmo tempo, este bioma é um dos mais destruídos, direta ou indiretamente, pelas atividades humanas, como por exemplo, a conversão destas áreas naturais em monoculturas (RIBEIRO et al., 2009).

No Centro de Endemismo de Pernambuco, uma sub-região da Floresta Atlântica ao norte do Rio São Francisco, as plantações de eucaliptos começaram a ser introduzidas nos anos de 1980. Entre as principais finalidades destas plantações está a produção de celulose, chapas e serrados, além da utilização da madeira como fonte de energia para outras aplicações como, por exemplo, produção de biomassas para caldeiras industriais, diminuindo assim a utilização de árvores nativas (VITAL, 2007).

Embora as áreas de plantações de eucaliptos tenham ampliado seus territórios, poucas investigações têm sido feitas em relação à biodiversidade destas áreas em comparação com remanescestes de Floresta Atlântica. Dentre os estudos focados nesta questão, Silva et al. (2014) compararam a diversidade de insetos em áreas de Floresta Atlântica e plantações de eucaliptos no estado do Rio Grande do Sul e Umetsu e Pardini (2007) estudaram os pequenos mamíferos não voadores, sob este mesmo enfoque, no estado de São Paulo. Em todos esses trabalhos foram encontrados resultados muito heterogêneos.

Entre os organismos que prestam um importante serviço ambiental para a manutenção das florestas tropicais estão os morcegos. Estes pequenos mamíferos voadores apresentam elevada diversidade de espécies na região Nordeste do Brasil (GARCIA et al., 2014), sendo excelentes organismos para estudos ecológicos.

O objetivo do presente trabalho foi comparar a riqueza e a abundância de morcegos, bem como a variação sazonal em relação a estes parâmetros, em uma área de vegetação nativa e em uma plantação de eucaliptos dentro do domínio da Floresta Atlântica no Centro de Endemismo de Pernambuco.

\section{METODOLOGIA}

\section{Área de Estudo}

Morcegos foram amostrados entre agosto de 2015 e janeiro de 2016 em um fragmento de Floresta Atlântica preservado e uma área de plantação de eucaliptos no estado de Pernambuco, ambos com aproximadamente 60 hectares e situados na propriedade "Fazenda Veneza", pertencente à empresa de transformação de papel Ondunorte, no município de Moreno $\left(8^{\circ} 5^{\prime} 58^{\prime \prime} \mathrm{S}, 35^{\circ} 10^{\prime} 48^{\prime \prime} \mathrm{O}\right)$. As coletas foram realizadas seguindo o calendário lunar na fase crescente. A área de Floresta Atlântica nativa vem sendo preservada desde a década de 1970 e as plantações de eucaliptos foram introduzidas na propriedade na década de 1990, com o objetivo de utilizar a biomassa como energia nas caldeiras da indústria Ondunorte. As plantações de eucaliptos apresentam entre três e oito anos de idade.

As espécies de eucaliptos cultivadas na área de estudo são Corymbia citriodora, Eucalyptus camaldulensis e Eucalyptus alba. O corte destas árvores ocorre entre três e seis anos, dependendo do diâmetro do tronco. 


\section{Amostragem dos Morcegos}

Os morcegos foram amostrados por oito dias, sendo metade em cada um dos dois locais, igualmente distribuídos entre a estação de maior e menor pluviosidade. As coletas foram realizadas com cinco redes de neblina do tipo mist-net de 12 metros de comprimento. Em cada dia de amostragem as redes permaneceram abertas das 17 às 22 horas. Para as coletas de morcegos dispomos da licença permanente do SISBIO/ICMBio n 00020383.

A identificação dos exemplares foi realizada através de literatura especializada, tal como o trabalho de Vizotto; Taddei (1973), que se baseia em caracteres externos e fórmulas dentárias para identificação dos espécimes de morcegos.

Para avaliar diferenças significativas na riqueza e abundância de morcegos entre os locais e entre as estações foi aplicado o teste de Qui-quadrado com $95 \%$ de confiança $(p<0,05)$ com o auxílio do software BioEstat versão 5.3, 2007.

\section{RESULTADOS E DISCUSSÃO}

Nos oito dias de amostragem foram capturados 55 morcegos no fragmento de Floresta Atlântica (FFA) e 24 na plantação de eucaliptos (PEU), contabilizando seis espécies. Na Tabela 1 estão representadas as espécies coletadas nos períodos seco e chuvoso.

Todas as espécies amostradas pertencem à família Phyllostomidae, para a qual todas as subfamílias conhecidas para o Brasil foram representadas neste estudo, com maior abundância de Carolliinae (60\% - FFA; 62,5\% - PEU), seguida por Stenodermatinae (29,1\% - FFA; 37,5\% PEU) e Phyllostominae, representada apenas na área de Floresta Atlântica (10,9\%), Tabela 1.

Tabela 1. Espécies de morcegos (Chiroptera) e suas respectivas abundâncias na estação seca e chuvosa em uma área de Floresta Atlântica e em uma área de plantação de eucaliptos entre agosto de 2015 e janeiro de 2016. Coletas realizadas na propriedade particular da empresa Ondunorte no município de Moreno, Pernambuco.

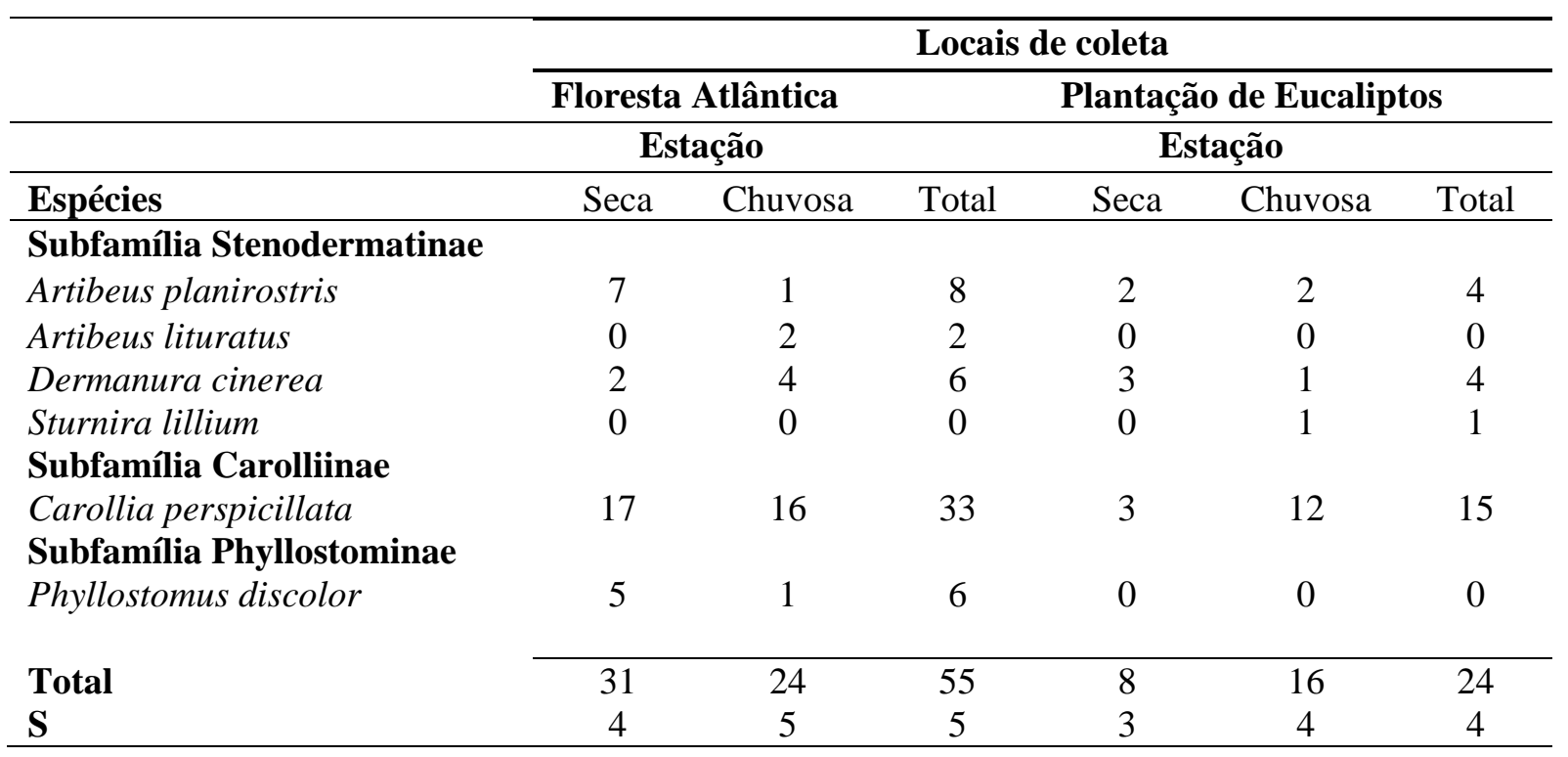

No período chuvoso foram registradas cinco espécies na área de Floresta Atlântica e quatro no eucaliptal, enquanto no período seco foram registradas três espécies no eucaliptal e quatro na floresta nativa (Tabela 1).

Não foram observadas diferenças significativas na riqueza de espécies entre os locais e entre as estações $\left(x^{2}=0,004, \mathrm{gl}=1, \mathrm{p}=0,9494\right)$. Artibeus lituratus e Phyllostomus discolor foram 
registrados apenas na área de Floresta Atlântica. Sturnira lillium foi registrada somente no eucaliptal, Tabela 1.

Em relação à abundância não observamos diferenças significativas entre as duas áreas de estudo $\left(x^{2}=6,287, \mathrm{gl}=5, \mathrm{p}=0,2793\right)$. Da mesma forma, não foram encontradas diferenças significativas na abundância em relação à sazonalidade $\left(x^{2}=9,989, \mathrm{gl}=5, \mathrm{p}=0,0755\right)$.

Foi observado que não existem diferenças entre os ambientes, isto pode ser explicado parcialmente já que a plantação de eucaliptos apresenta uma mistura com outras espécies de plantas como, por exemplo, da família Myrtaceae, Syzygium cumini (azeitona preta, jamelão ou jalão) e Psidium sp. (araçá). Também foram observadas uma espécie arbustiva da família Melastomataceae (Clidemia urceolata), uma espécie da família Cyperaceae (Cyperus rotundus) e uma da família Poaceae (Pennisetum sp.)

Nossos resultados não registraram diferenças significativas na riqueza entre as áreas de Floresta Atlântica e plantação de eucaliptos e entre as estações. Na Floresta Atlântica do sul do Brasil, Silva et al. (2014) observaram maior riqueza e abundância de insetos em áreas de plantação de eucaliptos em relação à floresta nativa. Os autores observaram maior abundância de insetos na área de floresta nativa no verão e na plantação de eucaliptos no outono e no verão. Law et al. (2011) compararam à diversidade de morcegos entre plantações nativas e de eucaliptos na Austrália. Assim como no presente estudo, os autores mencionaram que a riqueza e abundância foram maiores em áreas de floresta nativa em relação à plantação de eucaliptos. Os autores ressaltaram maior abundância de morcegos nas duas áreas na primavera e verão e menor no outono.

\section{CONCLUSÃO}

Não foram observadas diferenças significativas entre a abundância e a riqueza de morcegos nas duas áreas investigadas. Da mesma forma, não foram observadas diferenças significativas na sazonalidade na área de Floresta Atlântica e na plantação de eucaliptos.

\section{REFERÊNCIAS}

GARCIA, A. C. L.; LEAL, E. S. B.; ROHDE, C.; CARVALHO-NETO, F. G.; MONTES, M. A. The bats of northeastern Brazil: a panorama. Animal Biology, v. 64, p. 141-150, 2014.

GARDNER, T. A.; BARLOW, J.; CHAZDON, R.; EWERS, R. M.; HARVEY, C. A.; PERES, C. A.; SODHI, N. S. Prospects for tropical forest biodiversity in a human-modified world. Ecology Letters, v. 12, p. 561-582, 2009. http://dx.doi.org/10.1111/j.1461-0248.2009.01294.x

LAW, B. S.; CHIDEL, M.; PENMAN, T. Do young eucalypt plantations benefit bats in an intensive agricultural landscape? Wildlife Research, v. 38, p. 173-187, 2011.

PROENÇA, V. M.; PEREIRA, H. M.; GUILHERME, J.; VICENTE, L. Plant and bird diversity in natural forests and in native and exotic plantations in NW Portugal. Acta Oecologica, v. 36, p. 219-226, 2010. http://dx.doi.org/10.1016/j.actao.2010.01.002

RIBEIRO, M. C.; METZGER, J. P.; HIROTA, M. M. The Brazilian Atlantic Forest: how much is left, and how is the remaining forest distributed? Implications for conservation. Biological Conservation, v. 142, p. 1141-1153, 2009.

SILVA, E. R.; BUSATTO M.; LAZAROTTO, D. C.; COLDEBELLA, I. J.; MANSUR, G. G. Comunidades de insetos em fragmentos de Floresta Atlântica e cultura de Eucalyptus grandis no Sul do Brasil. Revista Biociências, v. 20, n. 1, p. 30-38. 2014. 
TURNER. I. M. The ecology of trees in the tropical rain forest. 1. ed. Cambrigde University Press, 2001.

UMETSU, F.; PARDINI, R. Small mammals in a mosaic of forest remnants and anthropogenic habitats-evaluating matrix quality in an Atlantic forest landscape. Landscape Ecology, v. 22, p. 517-530, 2007.

VITAL, M. H. F. Impacto ambiental de florestas de eucalipto. Revista do BNDES, v. 14, n. 28, p. 235-276, 2007.

VIZOTTO, L. D.; TADDEI, V. A. Chave para determinação de quirópteros brasileiros. Boletim Ciência, v. 1, p. 1-72, 1973. 